\title{
ARTICLE
}

\section{How evolutionary thinking can help us to understand ADHD}

\author{
Annie Swanepoel, Graham Music, John Launer \& Michael J. Reiss
}

\section{Annie Swanepoel is a}

consultant child and adolescent psychiatrist in Hertfordshire. She also holds a PhD in human physiology and is particularly interested in the integration of body and mind, nature and nurture, psychoneuroimmunology, as well as evolutionary science. Graham Music is a consultant child and adolescent psychotherapist at the Tavistock Clinic in London and an adult psychotherapist in private practice. He supervises and teaches on many courses, has a particular interest in the interface between developmental science and clinical work, and his publications include Nurturing Natures (2011) and The Good Life (2014). John Launer is

Associate Dean at Health Education England and an honorary lifetime consultant at the Tavistock Clinic. He is a doctor, family psychotherapist and writer. His principal interests include clinical supervision for the health professions, narrative medicine and evolutionary psychology. Michael J. Reiss is Professor of Science Education at the UCL Institute of Education and a Fellow of the Academy of Social Sciences. A priest in the Church of England and the former Director of Education at the Royal Society, he has written extensively about curricula, pedagogy and assessment in science education, sex education and bioethics.

Correspondence Dr Graham Music, Child and Family Department, Tavistock and Portman NHS Trust,

120 Belsize Lane, London NW3 5BA UK. Email: gmusic@tavi-port.nhs.uk.

\section{Copyright and usage}

(C) The Royal College of Psychiatrists 2017.

\begin{abstract}
SUMMARY
We argue that current debates about attentiondeficit hyperactivity disorder (ADHD) can be considered afresh using an evolutionary lens. We show how the symptoms of ADHD can often be considered adaptive to their specific environment. We suggest that, from an evolutionary point of view, ADHD symptoms might be understood to result from an 'evolutionary mismatch', in which current environmental demands do not fit with what evolution has prepared us to cope with. For example, in our ancestral environment of evolutionary adaptedness (EEA), children were not expected to sit still and concentrate on academic tasks for many hours a day. Understanding ADHD in terms of such a 'mismatch' raises significant issues regarding the management of childhood ADHD, including ethical ones. An approach based on the concept of mismatch could provide an alternative to current debates on whether ADHD results from nature or nurture and whether it is under- or over-diagnosed. It would allow clinicians and policy makers to take both the child and the environment into account and consider what might be desirable and feasible, both in society and for specific children, to lessen the mismatch.
\end{abstract}

\section{LEARNING OBJECTIVES}

- Grasp the concept of ADHD as an 'evolutionary mismatch'

- Understand the issues raised by this perspective, including ethical ones

- Appreciate how a transparent discussion of these issues might inform decisions about management, medication and schooling

\section{DECLARATION OF INTEREST}

The authors are members of the evopsychotherapy study group at the Tavistock Clinic. The aim of the group is to promote evolutionary thinking in psychotherapy and psychiatry.

Few childhood conditions designated as psychiatric disorders are as mired in controversy as attention-deficit hyperactivity disorder (ADHD) (Timimi/Taylor 2004). Diagnosis is generally made on the basis of behavioural checklists, and there are continual debates about the status of such diagnoses. Some mental health professionals see ADHD as a developmental disorder, some as genetically driven and some as a set of symptoms that are indistinguishable from the effects of childhood trauma.

In a previous article in BJPsych Advances (Swanepoel 2016) we argued that the traditional disease model, still dominant in psychiatry, is less than ideal for making sense of a range of psychological issues, such as the effects of early childhood experiences on development. We argued that a model based on evolutionary thinking can deepen understanding and aid clinical practice by showing how behaviours, bodily responses and psychological beliefs tend to occur for reasons that are evolutionarily adaptive, even when these might on first appearance seem pathological.

In the present article we apply this reasoning to ADHD, the most commonly diagnosed neurodevelopmental disorder (Thapar 2016). ADHD, characterised by hyperactivity, impulsivity and inattention, appears to be linked to serious consequences, including educational failure, substance misuse and criminal involvement. The prevalence of diagnosis seems to be increasing, but the reasons for this are hotly disputed (Thapar 2016).

Here, we do not argue for a single explanation for the widespread occurrence of ADHD. Indeed, we caution against too simplistic an understanding of the condition - including a belief either that all ADHD diagnoses are faulty or that the condition can always be objectively identified and straightforwardly treated with medication. Our hope is that an evolutionary perspective will prove useful to clinicians and others faced with high rates of referral of children (or adults) presenting with symptoms of ADHD. We argue that the environment of evolutionary adaptedness (EEA) did not prepare children to sit still and concentrate for hours every day and that the difficulties that many children experience can be understood in terms of this mismatch (Box 1).

\section{ADHD classification and identification}

In DSM-4, ADHD fell under 'disruptive behaviour disorders', along with oppositional defiant disorder, intermittent explosive disorder and conduct 


\section{BOX 1 Evolutionary mismatch}

When the environment in which an organism lives is significantly different from that in which it evolved, traits that were once adaptive may become pathological. This is termed an 'evolutionary mismatch' (Cofnas 2016). One example is that humans evolved to survive food scarcity by craving and eating high-calorie foods when these were available. In the current environment of generally plentiful food, this leads to widespread obesity. Thus, a trait that may have conferred survival advantage in the past may lead to vulnerability to disorder if the environment changes.

disorder. In DSM-5, ADHD was moved into the category of neurodevelopmental disorders, alongside autism spectrum disorders, intellectual disabilities, communication disorders and motor disorders. A neurodevelopmental disorder is one in which 'the development of the central nervous system is disturbed' (American Psychiatric Association 2013). Common characteristics of ADHD are that onset is in early childhood, that there are cognitive as well as behavioural deficits, and that the symptomatic and functional impairments tend to persist. There is typically a preponderance among males of both neurodevelopmental disorders in general and ADHD in particular, and these disorders tend to have a degree of heritability. There is a large overlap of different neurodevelopmental disorders - co-occurrence is the rule rather than the exception (Dyck 2011; Posner 2014).

In support of a neurodevelopmental view, the Ben-Gurion infant development study showed that sons of fathers with ADHD were more irritable than sons of fathers without ADHD (Auerbach 2004). The at-risk infants also indicated less clearly what was bothering them, making parenting them more difficult, as evidenced by more inadequate responses to their needs. This was confirmed by Elberling et al (2014), who found that motherinfant interaction problems were more likely with at-risk infants. Interestingly, expressed emotion (parental hostility) is child-specific, not parentspecific (Cartwright 2011).

In two large clinic samples of young people diagnosed with ADHD before school age, only $10 \%$ were in the 'normal' range of functioning at 15-18 years old - thus there appears to be continuity (Lahey 2016). Persistent classroom inattention is a strong predictor of not obtaining a high school diploma by age 22 (Pingault 2011). ADHD in preschool boys has been associated with a 10-point reduction in General Certificate of Secondary Education (age 16) scores (Washbrook
2013). A 7-12 point average IQ deficit has been noted in individuals with ADHD (Simonoff 2007), although there is considerable variability and some individuals with ADHD have an IQ well above average. It has also been shown that preschool ADHD incurs a 17-fold greater economic burden due to increased needs in education, health and social care and makes it more likely that children will be bullies or the victims of bullying (Verlinden 2015).

There appear to be no discernible differences in the brains of infants with ADHD compared with those of unaffected infants (Ghassabian 2013); however, by 6-8 years of age, children with ADHD had thinner cortices in the primary somatosensory area (Mous 2014). Adults with ADHD have also been found to show abnormal reactivity in this area (Dockstader 2009), although new studies show that there is not necessarily continuity between childhood and adult ADHD. Some have argued that the criterion that ADHD must have started before the age of 12 should therefore be dropped (Caye 2016).

\section{Epidemiological issues}

One notable fact about ADHD is that rates of recognition, diagnosis and treatment vary widely between and within countries. In 2012, at least 9\% of school-aged children in the USA were diagnosed with ADHD; the corresponding figure for France was less than 0.5\% (Wedge 2012). The rate of $\mathrm{ADHD}$ diagnosis in preschool children varies too, even between quite similar countries: in Denmark it is $1 \%$ (Elberling 2016), whereas it is 3.8\% in Iceland (Gudmundsson 2013). The rates even differ substantially across states in the USA (Fulton 2015). They have also increased considerably in many countries, including the USA and UK, in recent decades. Such variations may be due to differences in how the condition is defined and the ways data are gathered (Polanczyk 2014).

Another significant finding about ADHD is that, in large samples in many countries, there is a hugely increased likelihood of the diagnosis if a child is in the youngest group in a school year cohort. For example, children in Denmark born just before the cut-off for the next year were about 2.5 times more likely to have an ADHD diagnosis than their older classmates (Krabbe 2014), and similar results have been seen in a number of other countries, including Germany (Schwandt 2016), Canada (Chen 2015), Taiwan (Chen 2016) and Israel (Hoshen 2016). At the very least, this suggests an increase in diagnoses in children who are less emotionally mature and less able to be still. 
There are also cultural differences in diagnosis rates (Ghosh 2015), which might be explained by a range of factors. Some cultures place a higher value on emotion regulation, for example, so that problems with self-regulation is more common among US than Asian males (Wanless 2013). Cultures that value close bodily contact and a quick response to signals of distress, and where there are clear imperatives for children to abide by rules, are ones in which self-regulation tends to develop earlier and more fully. Children in more interdependent cultures are generally also quicker to develop skills in compliance and emotion regulation (Wanless 2013). Despite these cultural variations, it is nevertheless clear that there is a group of children, principally boys, who show symptoms (identified as ADHD) that cause concern and whose longer-term trajectories might not be good (Thapar 2016).

\section{Genes, epigenetics and adaptation}

According to evolutionary thinking, behaviour traits that have survived and been passed down the generations must have had adaptive value in the past, and possibly still have today. It is certainly conceivable, for example, that more adventurous individuals in hunter-gatherer society sometimes did better in terms of having viable offspring, perhaps because those individuals were more willing to explore (Box 2). It is worth asking why it could be adaptive for a child to have a version of a gene or set of genes that appears to give rise to such a poor prognosis as ADHD. It seems that such a 'temperament' might well be advantageous in some environments. For example, when we examine the genes of descendents of people involved in major migrations of the distant past, we see that a higher proportion than average have

BOX 2 How a gene associated with ADHD may have been adaptive: an example

About one-seventh of a Kenyan tribe, the Ariaal, have the long version of the DRD4 gene, which is associated with novelty-seeking. Pastoralists, some Ariaal still lead a nomadic life, moving from place to place, whereas others now have a more settled way of living. A study found that men with the novelty-seeking allele who lived a nomadic life were well nourished and healthy. In contrast, those with this same allele living a settled life were on average less well nourished (Eisenberg 2008). It seems that having the 'ADHD-inducing' variant might well be a better option when living a less settled kind of life, and that different genetic variations aid survival or success in some environments but not others. the same 'novelty-seeking' genetic variant that is associated with ADHD in children (Matthews 2011). One can speculate that being a carrier of that novelty-seeking variant might have aided the likelihood of survival by making such individuals more predisposed to seek new pastures when danger loomed, and hence survive to pass on this variant.

Although genes alone are most unlikely to cause ADHD symptoms, gene-environment interaction is looking increasingly likely to play a central role. It seems, for example, that carriers of the long allele (7-repeat allele) of the dopamine $\mathrm{D}_{4}$ receptor gene DRD4 are more likely to show ADHD symptoms (Faraone 2001) and this genetic variant also increases the likelihood that children will be novelty-seeking. For these children, insensitive parenting in the early years predicts more externalising behaviours, although this is not the case for carriers of the short variant (Windhorst 2015). Inheriting this allele also predicts poorer emotion regulation, and indeed more likelihood of disorganised attachment styles (Pappa 2015). Thus, this and other genes may predispose for ADHD, but will only ever be a partial explanation.

Interestingly, one study looked at hyperactive children who were adopted (Harold 2013). Where these adopted children received sensitive and attuned parenting the symptoms of hyperactivity were not subsequently seen. As so often, we find that experiences and genes, nature and nurture interact to produce their effects (van Ijzendoorn 2015). Thus, what we are seeing is that some children are born with more genetic susceptibility for ADHD-type symptoms, but also that certain kinds of environmental influence, such as cultural values or parenting, including closely monitoring a child's behaviour, can hugely reduce the potential effects of genes that otherwise might give rise to worrying behaviours.

Epigenetic research is showing that some children are more susceptible to the influence of their environment than others, what Belsky and others have called 'the differential susceptibility to rearing' influence (Belsky 2004). Belsky has argued that successful reproduction of one's genes is more likely if some of one's offspring are more influenced by the current environment than others, because in such scenarios, in the face of both continuity and major change, those offspring will survive to pass on their genes. Thus, we should now think not of vulnerability genes (e.g. for ADHD), but rather in terms of relative plasticity (Belsky 2014), because some individuals are simply more influenced by experiences than others, owing at least in part to their genes. 


\section{Environmental influences}

There have been a number of studies linking quality of parenting to ADHD diagnosis, concluding that ADHD is related to insecure attachment relationships (e.g. Roskam 2014). What much research makes clear (and in accordance with common sense) is that if we expect the environment to be dangerous and unpredictable, we are less relaxed and more hypervigilant and jumpy. Thus, children who grow up in difficult circumstances may be more hyperactive and less likely to settle than children who are used to a relaxed and calm environment. Research (Tronick 2007) as well as infant observation over many decades, such as in the Tavistock model (Miller 1989), have shown how even young infants, when feeling less emotionally held, move around more and are less able to concentrate. Infants and children feel calm, more relaxed and stiller when their emotional and physiological states are regulated by an adult attuned to them. Studies show that having a stressful or traumatic childhood is highly predictive of being impulsive, emotionally dysregulated and having poor executive functioning (Ersche 2012). In families displaying high levels of negativity, anger or aggression, children tend to struggle much more with emotion regulation (Morris 2007). Indeed, where there is violence and aggression we see extreme sympathetic nervous system arousal together with externalising behaviours (Panzer 2005; El-Sheikh 2009).

From the perspectives of life history theory (Belsky 2012), a speeded up metabolism, less trust, less relaxation, and more suspicion and risk-taking might be adaptive for abusive homes or violent neighbourhoods. In such environments there is little emotional security or expectation that things will work out well. It is a strategy that ensures short-term survival, though at the cost of long-term physical and mental health. Our responses can therefore be seen as adaptive to our environments, triggering neurobiological patterns that have a profound effect on the rest of our lives (Belsky 2012). Those born into highly stressed worlds tend to have a speeded up metabolism and more activated stress response systems and develop what some call a 'fast', as opposed to a 'slow', life history strategy. We see this in a range of other mammals as well as in humans, and it is a strategy that aids survival. Without it, any too trusting and complacent ancestors might well have met a violent end before they had time to reproduce. In many circumstances the best response is to be wary, vigilant and untrusting.

Evidence shows that ADHD symptoms increase in response to adverse social and economic as well as parenting influences. For example, Mischel (2014) found that children from low-income families in violent parts of New York's Bronx tended to have below average ability to self-regulate compared with more privileged children. Early severe institutional deprivation is associated with adult ADHD (Kennedy 2016). Other studies have found a link between low socioeconomic status and impaired development of the executive parts of the brain (Noble 2005), even linking poverty to chronic stress and neurocognitive outcomes right into adulthood (Evans 2009). Indeed, by the age of 6 months, infants from socioeconomically deprived environments have been shown to be less able to pay attention (Clearfield 2013). Childhood poverty and the associated stress levels can have a big effect on capacity for emotion regulation, the development of inhibitory brain networks (Kim 2013) and the likelihood of increased risk-taking (Griskevicius 2011). Being able to defer gratification depends on feeling sufficiently relaxed (high vagal tone) and being helped to bear and regulate one's emotions (Moore 2004).

ADHD can be thought of in part as a deficit in executive functioning (Barkley 2017) - although many forms of executive function disorder are unrelated to ADHD. Those diagnosed with ADHD struggle, for example, with planning, emotion regulation, focusing, concentrating, putting plans into action - all of which are aspects of executive functioning (Brown 2013). People able to delay gratification have more activity in prefrontal brain regions, central to abstract thinking, planning, working memory and emotion regulation - again, all of which are aspects of executive functioning (Barkley 2012). Those with more impulsive character traits tend to lack these prefrontal 'brakes' on their impulsivity (McClure 2004). Instead, more primitive subcortical brain areas are active. This also is seen in trauma and in stressful situations generally, which is partly why many children who display symptoms that fit with ADHD checklists for other reasons are misdiagnosed as having ADHD (DeJong 2010).

\section{Gender-based differential rates}

Why are rates of ADHD typically higher in males than in females? One common evolutionary explanation for differential rates such as this is that males have had to be more risk-taking to compete for mates, since a higher proportion of males than females fail to have children and pass on their genes. Thus, sexual competition between adult males is high, and this can be compounded when males have to leave their families to seek out mates. 
Also, research might suggest a trade-off in evolutionary history between the need to be risktaking and explore and the capacity to concentrate and be still. For example, boys seem to be more sensitive than girls to the consequences of suboptimal parental care. From birth onwards girls on average are better equipped to regulate their emotions and are less badly affected by disruptions in parenting. Parents may need to work harder to imitate and respond to their sons than to their daughters, and researchers have suggested that boys need more input in order to feel emotionally regulated (Tronick 2000). Following maternal postnatal depression it seems that boys tend to fare worse, having less capacity for object constancy at 18 months and showing more behavioural problems at school age (Murray 1993). Sander (2007) looked at newborns separated from their parents and placed with new carers. After a few days the girls had all entrained to their new carers' day-night rhythms, but the boys took several days longer to adjust, suggesting that they were more vulnerable to disruptions of care.

Tronick (2007) found that mothers with depression consistently showed angrier emotional expressions to their sons than to their daughters. By 6 months the boys were gesturing more anxiously and were three times more likely than the girls to resort to self-comforting strategies such as sucking their thumbs. It seems that boys generally are more demanding of their interactive partners. A study in France showed that mothers with a propensity for depression were more likely to become depressed if they had male babies (de Tychey 2008), who were presumably more demanding than female ones.

\section{Social changes}

Some ADHD symptoms might still (in contemporary society) make adaptive sense, such as being vigilant and wary in the face of violence and prioritising survival and safety over the higher executive functions such as empathy, self-reflection and emotion regulation (Music 2016).

However, the social environment for children has changed dramatically over the past century or two. Whereas most boys would once have typically learnt a trade from their father or another relative, this all changed with the professionalisation of schooling. One result is that there is a mismatch between the strengths of children with ADHD - i.e. their tendency to explore, to challenge and to try out new ways of doing things - and their environment (today's schools). ADHD is unusual in that its diagnosis is most often made in the context of schooling, with most cases being diagnosed in children between the ages of 6 and 12 (NHS Choices 2016).

The standard model of schooling, in which 20 or more young people of the same age are taught in classrooms for about 5 hours a day, 5 days a week, 200 days of the year from age 6 to 16 , certainly runs counter to our evolved behavioural strategies. Furthermore, a child's ADHD symptoms will affect other children in the room and the teacher's very capacity to teach. As the website ADHD Solutions (2017) puts it: 'a child with ADHD can be extremely challenging'. Schooling therefore favours some young people at the expense of others, including those with ADHD. To add to this, schools, especially primary schools, can be seen as feminised institutions, the large majority of teachers being women. Indeed, in England in $2015,80 \%$ of the total teaching workforce in state-funded schools (primary and secondary) was female (Department for Education 2016). As we have noted, ADHD predominantly affects males: a 2006 survey reported male:female prevalence of child and adolescent ADHD varying from 3:1 in Norway to 16:1 in Austria (ADHD Institute 2016). This gender imbalance decreases in adulthood. It is likely that schools typically favour the sorts of fairly passive, acquiescent behaviour that society all too often deems particularly appropriate for females.

\section{Treatment}

\section{Treatment types}

The main treatments for ADHD are medication and psychological interventions. Methylphenidate can improve irritability in ADHD (Fernández de la Cruz 2015), and a Cochrane meta-analysis showed that it also improves teacher ratings of $\mathrm{ADHD}$ and does not have serious adverse side-effects, although the data quality is poor (Storebø 2016). Psychological interventions for ADHD show small effects on non-blinded outcome ratings, but no effect on blinded ratings (Abikoff 2015).

There is accordingly much controversy about the medication of $\mathrm{ADHD}$, with two main opposing camps. On the one hand, there is some evidence to show that ADHD has a biological component and responds to medication (at least in the short term) and that children who are treated generally have better educational outcomes and are less likely to misuse drugs or get in trouble with the law (Thapar 2016). On the other hand, many clinicians argue that normal children are being medicated to make them compliant and 'less naughty' and that medication is being used as a form of social control. Even among ourselves as authors, we are not of one mind on this matter. 
Newer evidence reveals a differential susceptibility to the development of oppositional defiant disorder and conduct disorder in children genetically more susceptible to developing ADHD (Bakermans-Kranenburg 2015). The efficacy of interventions might be underestimated or even go undetected as a main effect when it is hidden in gene-by-environment $(\mathrm{G} \times \mathrm{E})$ analysis. These children will be more likely to develop ADHD and the attendant serious behavioural complications if experiencing low warmth in their relationships with their caregivers - but will be less likely than average children to develop these difficulties if they experience warm parenting. It is therefore too simplistic to just link genetic traits to outcomes: once again, there are significant gene-environment interactions at play.

\section{Ethics}

From an ethical point of view, a serious question needs to be asked: 'Should psychiatrists prescribe medication to help a child to fit into an environment that is not ideal?' Many ADHD services do not have any behavioural support services to which they can refer. This puts pressure on psychiatrists to prescribe, even if psychological or social measures might be more appropriate. It is also questionable whether prescribing is ethically justifiable when it is undertaken because of the shortcomings of the school environment. Furthermore, there is often a clear conflict of interest between what is best for the child and what is easiest for parents and teachers. In a rare study that examined the views of children with ADHD, Singh (2012) found that, in both the UK and the USA, children wanted more treatment options outside of medication, but that these were not available. The question of informed consent becomes difficult with younger children, who are completely dependent on their parents. More widely, there are important ethical considerations to be addressed by health, education and social care services (Richards 2013). Some of the complexities that can arise are illustrated by the case vignettes in Box 3.

\section{Conclusions}

We believe that an evolutionary perspective, which points out the mismatch between biological predispositions and current environments, including schools, has a lot to add to debates about ADHD diagnosis and treatment. This paves the way for a more informed discussion about whether to medicate or not. Understanding ADHD as a biological variant in some individuals that has adaptive value for living in unpredictable situations may help shift perceptions of the child
BOX 3 The range and complexities of children with ADHD: case vignettes ${ }^{a}$
Redressing the mismatch

Alex is 17 years old. He was diagnosed with ADHD at age 8 and treated with stimulant medication until he finished his GCSEs at 16 He was able to stop using medication when he went to a football college. He explained that at college they do 2 hours of football training and then break for an hour of, say, maths, before doing another 2 hours of training and then having a lesson of English. and he was able to sit still and concentrate without needing medication.

\section{The influence of nurture}

Nine-year-old Joe, who was on a local authority child protection plan because of neglect by his drug-misusing mother, was treated with stimulant medication for ADHD. After he was placed in foster care, his school work improved dramatically and he was able to stop his medication. One of the reasons for this was that the 'breakfast' his mother had assured professionals she was giving him with his stimulant medication before school consisted of a can of caffeinated energy drink. He said that this worked very well for him

\section{Successful use of medication}

Mohammed, 14 years old, was on the verge of exclusion from school because of his disruptive behaviour in class, fighting in the playground and rudeness to teachers. He had been diagnosed with ADHD at age 8 , but his parents had been opposed to medication. The family now agreed to a trial of stimulant medication, which was a resounding success. The boy explained that he was now able to concentrate and think before he acted. He thrived on the positive feedback he was getting at school and his behaviour and attainment improved.

Treat the environment, not the child Seven-year-old Alfie was being treated with short-acting ADHD medication to cover him at school, but neighbours in the flat below complained about his jumping around in the evenings and at the weekends. Members of the multidisciplinary team agreed that medication should not be prescribed in this instance and decided to write a letter to the local housing office instead.

a. Thesechildren are fictitious, butrepresentative of individuals we meet in clinical practice. as being 'naughty' to seeing someone caught in an evolutionary mismatch. Behavioural strategies in school, for example, could then focus on allowing the child plenty of physical activity and a fidget toy to fiddle with when they have to sit still, as well as making eye contact with the child before giving instructions and keeping instructions single and simple (for further suggestions see LD Online 2017). Over the longer term, we may need to rethink how schools are organised, conceptualised and run. Increasingly, the emphasis in schooling is only on academic subjects. Subjects that involve movement and the development of physical skills (physical education, metalwork, home economics, etc.) have largely disappeared from the curricula in a number of countries.

It may help for adults with ADHD to understand what their strengths are and to seek jobs where these are valued, for example in sport, adventure tours, the military or any other job where physical activity and rapid decision-making are highly valued.

Of course, there are downsides to having ADHD - individuals are more likely to perform poorly in cognitive tasks, die in accidents and become involved in criminal activity. They are also more 
likely to follow a fast life history strategy and tend to have more children at a younger age in whom they invest less - this may lead to an intergenerational transmission of problem behaviours linked to a biological susceptibility to ADHD (Thapar 2016).

In sum, we believe that an evolutionary view can help both professionals and patients understand ADHD in a broader sense, where it can be thought of as both a liability and a strength and where attempts are made to adapt the environment before resorting to medication to adapt the individual.

\section{References}

Abikoff HB, Thompson M, Laver-Bradbury C, et al (2015) Parent training for preschool ADHD: a randomized controlled trial of specialized and generic programs. Journal of Child Psychology and Psychiatry, 56: 618-31.

ADHD Institute (2016) Epidemiology: Gender. ADHD Institute (http:// adhd-institute.com/burden-of-adhd/epidemiology/gender/). Accessed 15 September 2017

ADHD Solutions (2017) ADHD in childhood. ADHD Solutions (http:// cmsms.adhdsolutions.org/index.php?page=adhd-at-home). Accessed 15 September 2017

American Psychiatric Association (2013) Diagnostic and Statistical Manual of Mental Disorders (5th edn) (DSM-5). APA

Auerbach JG, Atzaba-Poria N, Berger A, et al (2004) Emerging developmental pathways to ADHD: possible path markers in early infancy. Neural Plasticity, 11: 29-43.

Bakermans-Kranenburg MJ, van IJzendoorn MH (2015) The hidden efficacy of interventions: gene $\times$ environment experiments from a differential susceptibility perspective. Annual Review of Psychology, 66: 381-409.

Barkley RA (2012) Executive Functions: What They Are, How They Work and Why They Evolved. Guilford Press

Barkley RA (2017) Attention-Deficit Hyperactivity Disorder: A Handbook for Diagnosis and Treatment (4th edn). Guilford Press.

Belsky J (2004) Differential susceptibility to rearing influence. In Origins of the Social Mind: Evolutionary Psychology and Child Development (eds B Ellis, D Bjorklund): 139-63. Guilford Press.

Belsky J, Schlomer GL, Ellis BJ (2012) Beyond cumulative risk: distinguishing harshness and unpredictability as determinants of parenting and early life history strategy. Developmental Psychology, 48: $662-73$

Belsky J, Hartman S (2014) Gene-environment interaction in evolutionary perspective: differential susceptibility to environmental influences. World Psychiatry, 13: 87-9.

Brown TE (2013) A New Understanding of ADHD in Children and Adults: Executive Function Impairments. Routledge.

Cartwright KL, Bitsakou P, Daley D, et al (2011) Disentangling child and family influences on maternal expressed emotion toward children with attention-deficit/hyperactivity disorder. Journal of the American Academy of Child \& Adolescent Psychiatry, 50: 1042-53.

Caye A, Rocha TB, Anselmi L, et al (2016) Attention-deficit/hyperactivity disorder trajectories from childhood to young adulthood: evidence from a birth cohort supporting a late-onset syndrome. JAMA Psychiatry, 73: 705-12.

Chen K, Fortin N, Phipps S (2015) Young in class: implications for inattentive/hyperactive behaviour of Canadian boys and girls. Canadian Journal of Economics, 48: 1601-34.

Chen M-H, Lan W-H, Bai Y-M, et al (2016) Influence of relative age on diagnosis and treatment of attention-deficit hyperactivity disorder in Taiwanese children. Journal of Pediatrics, 172: 162-7.
Clearfield MW, Jedd KE (2013) The effects of socio-economic status on infant attention. Infant and Child Development, 22: 53-67.

Cofnas N (2016) A teleofunctional account of evolutionary mismatch. Biological Philosophy, 31: 507-25.

DeJong M (2010) Some reflections on the use of psychiatric diagnosis in the looked after or 'in care' child population. Clinical Child Psychology and Psychiatry, 15: 589-99.

Department for Education (2016) School Workforce in England: November 2015. Department for Education (https://www.gov.uk/government/ uploads/system/uploads/attachment_data/file/533618/SFR21_2016 MainText.pdf).

de Tychey C, Briançon S, Lighezzolo J, et al (2008) Quality of life, postnatal depression and baby gender. Journal of Clinical Nursing, 17: 312-22.

Dockstader C, Gaetz W, Cheyne D, et al (2009) Abnormal neural reactivity to unpredictable sensory events in attention-deficit/hyperactivity disorder. Biological Psychiatry, 66: 376-83.

Dyck MJ, Piek JP, Patrick J (2011) The validity of psychiatric diagnoses: the case of 'specific' developmental disorders. Research in Developmental Disabilities, 32: 2704-13

Eisenberg DTA, Campbell B, Gray PB, et al (2008) Dopamine receptor genetic polymorphisms and body composition in undernourished pastoralists: an exploration of nutrition indices among nomadic and recently settled Ariaal men of northern Kenya. BMC Evolutionary Biology, 8: 173.

Elberling $\mathrm{H}$, Linneberg A, Olsen EM, et al (2014) Infancy predictors of hyperkinetic and pervasive developmental disorders at ages $5-7$ years: results from the Copenhagen Child Cohort CCC2000. Journal of Child Psychology and Psychiatry, 55: 1328-35.

Elberling H, Linneberg A, Rask CU, et al (2016) Psychiatric disorders in Danish children aged 5-7 years: a general population study of prevalence and risk factors from the Copenhagen Child Cohort (CCC 2000). Nordic Journal of Psychiatry, 70: 146-55.

El-Sheikh M, Kouros CD, Erath S, et al (2009) Marital conflict and children's externalizing behavior: pathways involving interactions between parasympathetic and sympathetic nervous system activity. Monographs of the Society for Research in Child Development, 74: 1-79.

Ersche KD, Turton AJ, Chamberlain SR, et al (2012) Cognitive dysfunction and anxious-impulsive personality traits are endophenotypes for drug dependence. American Journal of Psychiatry, 169: 926-36.

Evans GW, Schamberg MA (2009) Childhood poverty, chronic stress, and adult working memory. Proceedings of the National Academy of Sciences, 106: 6545-9.

Faraone SV, Doyle AE, Mick E, et al (2001) Meta-analysis of the association between the 7-repeat allele of the dopamine D4 receptor gene and attention deficit hyperactivity disorder. American Journal of Psychiatry, 58: 1052-7.

Fernández de la Cruz L, Simonoff E, McGough JJ, et al (2015) Treatment of children with attention-deficit/hyperactivity disorder (ADHD) and irritability: results from the multimodal treatment study of children with ADHD (MTA). Journal of the American Academy of Child and Adolescent Psychiatry, 54: 62-70.

Fulton BD, Scheffler RM, Hinshaw SP (2015) State variation in increased ADHD prevalence: links to NCLB school accountability and state medication laws. Psychiatric Services, 66: 1074-82.

Ghassabian A, Herba CM, Roza SJ, et al (2013) Infant brain structures, executive function, and attention deficit/hyperactivity problems at preschool age. A prospective study. Journal of Child Psychology and Psychiatry, 54: 96-104.

Ghosh M, Holman CD, Preen DB (2015) Exploring parental country of birth differences in the use of psychostimulant medications for ADHD: a whole-population linked data study. Australian and New Zealand Journal of Public Health, 39: 88-92.

Griskevicius V, Tybur JM, Delton AW, et al (2011) The influence of mortality and socioeconomic status on risk and delayed rewards: a life history theory approach. Journal of Personality and Social Psychology, 100: 1015-26. 
Gudmundsson 00, Magnusson P, Saemundsen E, et al (2013) Psychiatric disorders in an urban sample of preschool children. Child and Adolescent Mental Health, 18: 210-7.

Harold GT, Leve LD, Barrett D, et al (2013) Biological and rearing mother influences on child ADHD symptoms: revisiting the developmental interface between nature and nurture. Journal of Child Psychology and Psychiatry, 54: 1038-46.

Hoshen MB, Benis A, Keyes KM, et al (2016) Stimulant use for ADHD and relative age in class among children in Israel. Pharmacoepidemiology and Drug Safety, 25: 652-60.

Kennedy M, Kreppner J, Knights N, et al (2016) Early severe institutional deprivation is associated with a persistent variant of adult attentiondeficit/hyperactivity disorder: clinical presentation, developmental continuities and life circumstances in the English and Romanian Adoptees study. Journal of Child Psychology and Psychiatry, 57: 1113-25.

Kim P, Evans GW, Angstadt M, et al (2013) Effects of childhood poverty and chronic stress on emotion regulatory brain function in adulthood. Proceedings of the National Academy of Sciences, 110: 18442-7.

Krabbe EE, Thoutenhoofd ED, Conradi M, et al (2014) Birth month as predictor of ADHD medication use in Dutch school classes. European Journal of Special Needs Education, 29: 571-8.

Lahey BB, Lee SS, Sibley MH, et al (2016) Predictors of adolescent outcomes among 4-6-year-old children with attention-deficit/ hyperactivity disorder. Journal of Abnormal Psychology, 125: 68-81.

LD Online (2017) Helping the Student with ADHD in the Classroom: Strategies for Teachers. WETA (http://www.Idonline.org/article/5911). Accessed 15 September 2017.

Matthews LJ, Butler PM (2011) Novelty-seeking DRD4 polymorphisms are associated with human migration distance out-of-Africa after controlling for neutral population gene structure. American Journal of Physical Anthropology, 145: 382-9.

McClure SM, Laibson DI, Loewenstein G, et al (2004) Separate neural systems value immediate and delayed monetary rewards. Science, 306 : $503-7$.

Miller L (1989) Closely Observed Infants. Duckworth.

Mischel W (2014) The Marshmallow Test: Understanding Self-control and How To Master It. Little, Brown and Company.

Moore C, Macgillivray S (2004) Altruism, prudence, and theory of mind in preschoolers. New Directions for Child and Adolescent Development, 2004 (103): 51-62.

Morris AS, Silk JS, Steinberg L, et al (2007) The role of the family context in the development of emotion regulation. Social Development, 16: 361-88.

Mous SE, Muetzel R1, El Marroun H, et al (2014) Cortical thickness and inattention/hyperactivity symptoms in young children: a population-based study. Psychological Medicine, 44: 3203-13.

Murray L, Kempton C, Woolgar M, et al (1993) Depressed mothers' speech to their infants and its relation to infant gender and cognitive development. Journal of Child Psychology and Psychiatry, 34: 1083-101.

Music G (2016) Nurturing Natures: Attachment and Children's Emotional, Social and Brain Development. Psychology Press.

NHS Choices (2016) Attention deficit hyperactivity disorder (ADHD). NHS Choices (http://www.nhs.uk/conditions/Attention-deficit-hyperactivitydisorder/Pages/Introduction.aspx). Accessed 27 October 2016.

Noble KG, Norman MF, Farah MJ (2005) Neurocognitive correlates of socioeconomic status in kindergarten children. Developmental Science, 8: 74-87.

Panzer A, Viljoen M (2005) Supportive evidence for ADHD as a neurodevelopmental disorder. Medical Hypotheses, 64: 755-8.

Pappa I, Mileva-Seitz VR, Bakermans-Kranenburg MJ, et al (2015) The magnificent seven: a quantitative review of dopamine receptor $\mathrm{d} 4 \mathrm{and}$ its association with child behavior. Neuroscience and Biobehavioral Reviews, 57: 175-86.
Pingault J-B, Tremblay RE, Vitaro F, et al (2011) Childhood trajectories of inattention and hyperactivity and prediction of educational attainment in early adulthood: a 16-year longitudinal population-based study. American Journal of Psychiatry, 168: 1164-70.

Polanczyk GV, Willcutt EG, Salum GA, et al (2014) ADHD prevalence estimates across three decades: an updated systematic review and meta-regression analysis. International Journal of Epidemiology, 43: 434-42.

Posner MI, Rothbart MK, Sheese BE, et al (2014) Developing attention: behavioral and brain mechanisms. Advances in Neuroscience, 1 May (doi: 10.1155/2014/405094).

Richards LM (2013) Is it time for a more integrated bio-psycho-social approach to ADHD? Clinical Child Psychology and Psychiatry, 18: 403503

Roskam I, Stievenart M, Tessier R, et al (2014) Another way of thinking about ADHD: the predictive role of early attachment deprivation in adolescents' level of symptoms. Social Psychiatry and Psychiatric Epidemiology, 49: 133-44.

Sander L (2007) Living Systems, Evolving Consciousness, and the Emerging Person: A Selection of Papers from the Life Work of Louis Sander. Routledge.

Schwandt H, Wuppermann A (2016) The youngest get the pill: ADHD misdiagnosis in Germany, its regional correlates and international comparison. Labour Economics, 43: 72-86.

Simonoff E, Pickles A, Wood N, et al (2007) ADHD symptoms in children with mild intellectual disability. Journal of the American Academy of Child \& Adolescent Psychiatry, 46: 591-600.

Singh I (2012) VOICES: Voices on Identity, Childhood, Ethics and Stimulants. Children Join the Debate. ADHD Voices.

Storebø OJ, Simonsen E, Gluud C (2016) Methylphenidate for attentiondeficit/hyperactivity disorder in children and adolescents. JAMA, 315: 2009-10.

Swanepoel A, Sieff DF, Music G, et al (2016) How evolution can help us understand child development and behaviour. BJPsych Advances, 22: 36-43.

Thapar A, Cooper M (2016) Attention deficit hyperactivity disorder. Lancet, 387: 1240-50.

Timimi S/Taylor E (2004) ADHD is best understood as a cultural construct (debate). British Journal of Psychiatry, 184: 8-9.

Tronick EZ, Weinberg MK (2000) Gender differences and their relation to maternal depression. In Stress, Coping, and Depression (eds SL Johnson, AM Hayes, TM Field, et all: 23-34. Lawrence Erlbaum Associates.

Tronick E (2007) The Neurobehavioral and Social Emotional Development of Infants and Children. Norton.

van ljzendoorn MH, Bakermans-Kranenburg MJ (2015) Genetic differential susceptibility on trial: meta-analytic support from randomized controlled experiments. Development and Psychopathology, 27: $151-62$

Verlinden M, Jansen PW, Veenstra R, et al (2015) Preschool attentiondeficit/hyperactivity and oppositional defiant problems as antecedents of school bullying. Journal of the American Academy of Child \& Adolescent Psychiatry, 54: 571-9.

Wanless SB, McClelland MM, Lan X, et al (2013) Gender differences in behavioral regulation in four societies: The United States, Taiwan, South Korea, and China. Early Childhood Research Quarterly, 28: 621-33.

Washbrook E, Propper C, Sayal K, et al (2013) Pre-school hyperactivity/ attention problems and educational outcomes in adolescence: prospective longitudinal study. British Journal of Psychiatry, 203: 265-71.

Wedge M (2012) Why French kids don't have ADHD. Psychology Today, 8 March (Blog: Suffer the Children).

Windhorst DA, Mileva-Seitz VR, Linting M, et al (2015) Differential susceptibility in a developmental perspective: DRD4 and maternal sensitivity predicting externalizing behavior. Developmental Psychobiology, 57 : 35-49.

\section{MCO answers}

$1 d \quad 2 b \quad 3 c \quad 4$ e $5 b$ 


\section{MCQs}

Select the single best option for each question stem

1 Viewing ADHD as an 'evolutionary mismatch' means that:

a there is a single explanation for the widespread occurrence of ADHD

$b$ all diagnoses of ADHD are faulty

c the condition can always be objectively identified

d previous selection pressures have not adapted us to our present environment

e diagnosis can made using behavioural checklists.

2 The fact that ADHD is so much rarer among children in France than in the USA is most likely due to:

a the presence of far more child psychiatrists in the USA compared with France

b different cultural presumptions between the two countries as to what behaviour constitutes ADHD

c better school food in France

d higher rates of teenage pregnancy in the USA

e higher rates of divorce in the USA.

3 The most likely explanation why younger children in a school year are more likely to be diagnosed with ADHD is that such children:

a are more likely to be bullied

b need to go to the toilet more often

c have more difficulties sitting still and paying attention to their teachers

$\mathrm{d}$ are behind their peers in respect of reading and writing

e are less likely to make friends with their peers.

4 It is not true that infants at high-risk of ADHD:

a are more irritable than controls

b signal their needs less clearly c are parented less effectively

d experience more hostility from their parents

e have parents who are more hostile in general.

5 According to evolutionary science, the high prevalence of ADHD in school-aged children can be explained by the concept of:

a fast life history, in which the emphasis is on ensuring short-term survival even if at the cost of long-term suffering

b mismatch, in which our ancestral environment did not prepare us for current environmental demands

c evolutionary trade-off between physical fitness and academic excellence

$\mathrm{d}$ natural selection of active children

e survival of the fittest, which favours children who can work on their own. 